\title{
JOVENS ESTUDANTES DO ENSINO MÉDIO E A HISTÓRIA EM SITUAÇÃO ESCOLAR ${ }^{1}$
}

\author{
Astrogildo Fernandes da Silva $\mathrm{Jr}^{2}$ \\ José Josberto Montenegro Sousa ${ }^{3}$
}

RESUMO: O presente texto tem como objetivo apresentar uma análise dos resultados de um projeto de pesquisa que consiste em um estudo que analisa o potencial das diferentes fontes e das diferentes linguagens da cultura contemporânea no processo de ensinar e aprender história, na perspectiva de contribuir para a formação cidadã de jovens estudantes do Ensino Médio. Em relação aos procedimentos metodológicos, recorre à observação de cunho etnográfico, à história oral e à didática da história. Concluiu-se que os usos de diferentes fontes e linguagens nas aulas de história do Ensino Médio podem constituir iniciativas, para promover articulação entre os saberes escolares e a vida prática dos jovens estudantes.

PALAVRAS-CHAVE: Juventude. Ensino de história. Ensino Médio. Diferentes fontes e linguagens.

1 Este artigo apresenta resultados de uma pesquisa apoiada pela FAPEMIG/ CAPES/CNPq Editais: MCTI/CNPq/MEC/CAPES n. 18/2012 e 13/2012 Pesquisa na Educação Básica Acordo CAPES e FAPEMIG; FAPEMIG Universal/2013.

2 Doutor em Educação pelo Programa de Pós-Graduação em Educação da Universidade Federal de Uberlândia. Professor do Curso de História na FACIP - Faculdades Integradas do Pontal - UFU, Campus Pontal.

3 Doutor em História Social pela Pontifícia Universidade Católica de São Paulo/ PUC-SP. Professor no curso de graduação em História da Universidade Federal de Uberlândia/UFU, Campus do Pontal/FACIP. 
ABSTRACT: This paper aims to present an analysis of the results of a research project consisting of a study that examined the potential of different sources and different languages of contemporary culture in the process of teaching and learning history in order to contribute to the civic education of young high school students. Regarding the methodological procedures, recourse to ethnographic observation, oral history and historical education were analyzed. It was concluded that the use of different didactic sources and languages in high school history classes can be initiatives to promote coordination between school knowledge and practical life of young students.

KEYWORDS: Youth. History teaching. High School. Didactic sources and languages.

\section{Introdução}

Juventude é um termo que nos parece óbvio, um assunto sobre o qual todos têm algo a dizer, afinal, todos nós somos ou fomos jovens um dia, ou convivemos com jovens. Entretanto, quando nos aprofundamos nos estudos sobre os significados, as dificuldades conceituais aparecem. Segundo Abramo e Branco (2005), "muito do que se escreve sobre juventude é para alertar para os deslizes, os encobertamentos, as disparidades e mistificações que o conceito encerra" (ABRAMO; BRANCO, 2005, p. 37).

Para Sposito (1997), a juventude, como categoria histórica e socialmente construída, tem sido considerada como fase da vida marcada por instabilidade associada a determinados problemas sociais. Segundo a autora, em linhas gerais, a juventude dos anos de 1960 era vista como um "problema", uma vez que era protagonista de uma crise de valores e de um conflito de gerações, essencialmente, situado sobre o terreno dos comportamentos éticos e culturais. Nos anos de 1970, os estudos sobre a juventude a transformaram em categoria econômica, isso devido 
aos "problemas" de emprego e de entrada na vida ativa, que caracterizaram essa década. Nos anos de 1980, as pesquisas sobre gangues ocuparam o interesse dos estudiosos, não só em virtude do decréscimo da visibilidade das manifestações anteriores, como em decorrência da escalada da violência juvenil. Nos anos 1990, a juventude foi caracterizada pela "transição" de uma geração que valorizava a organização, a articulação, a lógica e o raciocínio, para uma geração que cultua o corpo, o prazer, o fragmentário e o individual.

Vivemos na segunda década dos anos 2000, um período em que os jovens se colocam como uma categoria social que adquire outra visibilidade na cena cultural. Exprimem novas demandas, comportamentos, consumos, bem como um estilo de vida diferente. Ao longo deste tempo, a sociedade também experimentou consideráveis transformações, por vezes, premida pela necessidade de adaptar-se, outras de conter as novas demandas. Neste contexto, à escola designa a função primordial de promover a formação de crianças e jovens, preparando-os para inserção efetiva no mundo adulto. Em relação à escola, Dayrell (2007) destaca que os jovens a percebem como um espaço distante de seus interesses, associada a aspectos que a obsolescência de suas práticas, considerada enfadonha, com professores que pouco acrescentam à formação dos jovens, tornando-se cada vez mais uma "obrigação" necessária, tendo em vista a necessidade de diplomas. Nesse sentido, indagamos: como a história em situação escolar pode contribuir para a formação crítica dos jovens estudantes que cursam o Ensino Médio em escolas públicas? Qual o potencial das diferentes fontes e linguagens no processo de ensinar e aprender história?

Com o intuito de buscar possíveis respostas para tais indagações, neste texto, temos como objetivo apresentar uma análise dos resultados de um projeto de pesquisa desenvolvido por professores formadores, estudantes de História, em colaboração com um professor e alunos do Ensino Médio. Neste artigo, apresentamos resultados decorrentes do acompanhamento, durante três anos, do trabalho com diferentes fontes e diferentes 
linguagens da cultura contemporânea - filmes, canções, quadrinhos, obras de ficção, poesias, internet, documentos, história oral, dentre outras, no processo de ensino e aprendizagem em história, particularmente, o potencial destas na formação histórica de jovens estudantes do Ensino Médio.

\section{As trilhas percorridas: a perspectiva teórico-metodológica}

Antes de nos determos nas perspectivas metodológicas adotadas na pesquisa, consideramos relevante destacar que, ao longo do desenvolvimento do projeto, optamos por problematizar determinados modelos de ciência, caracterizados por métodos cristalizados, ancorados em princípio da neutralidade e previsibilidade, que engendram aquilo que Santos (2004) denomina "monocultura do saber". Santos (2004) refere-se a esse modelo de ciência como razão indolente e defende a necessidade de desafiá-lo. Nesse sentido, almeja-se uma ciência não linear que contemple as diversidades, as singularidades, complexidades do pensamento e da realidade. Para Santos (2004), a ruptura da razão indolente em favor da razão cosmopolita pressupõe com preponderância da cosmovisão ocidental que legitima o poder social, ao conceber noção de temporalidade, que, por um lado, contrai o presente e, de outro, expande o futuro, porém este é mantido no plano da contemplação. A contração do presente se estabelece por uma peculiar concepção de totalidade, a qual transformou o presente num instante fugidio, entrincheirado entre o passado e o futuro.

Com intuito de propor um viés distinto ao constructo epistemológico pretensamente hegemônico, imposto pela racionalidade europeia, Santos e Menezes (2010) atribuem ao colonialismo interferência em instâncias para além das formas de exploração e dominação pelas quais é conhecido, tem sido responsável pela disseminação de uma tutela epistemológica hierarquizante de saber-poder que conduziu à supressão de muitas formas de saber próprias de nações e povos colonizados, relegando uma diversidade de saberes à condição 
de subalternidade. Na cultura ocidental, adotou-se uma conduta pautada pela hierarquização de formas de conhecimento não europeias, assim como ignorou suas narrativas, visto que estas supostamente, não condiziam com parâmetros preestabelecidos pelas concepções de cunho cientificistas de matriz ocidental. Com isto, as populações submetidas ao processo de colonização foram interditadas, suas culturas e modos de ser e viver desarticulados. Em perspectiva semelhante, Mignolo (2003) assevera que o eurocentrismo funcionou como se não houvesse outras narrativas além das macronarrativas da civilização ocidental ou da modernidade europeia.

Esse "epistemicídio" tem sido denunciado por estudiosos vinculados ao pensamento da pós-colonialidade como uma das violências mais duradouras efetivadas durante o período colonial. Contrapondo-se ao colonialismo, Santos (2010) defende a noção de ecologia de saberes. Nesta, reconhece a existência de uma pluralidade de formas de conhecimento além do conhecimento científico. Para o autor, a ecologia de saberes expande o caráter testemunhal dos conhecimentos de forma a abranger igualmente as relações entre o conhecimento científico e o não-científico, alargando, deste modo, o alcance da intersubjetividade como interconhecimento e vice-versa. A proposta da descolonização dos saberes é caracterizada por um diálogo hermenêutico entre os diversos saberes. Parte do princípio de que a incompletude, própria de qualquer cultura ou conhecimento, seja não minorada, mas complexificada, em busca de sentidos.

As ponderações acima elencadas nos parecem inspiradoras para tratarmos do ensino de História, particularmente, quanto ao propósito de formularmos a crítica a sua estrutura curricular de caráter monocultural e eurocêntrico, caracterizado por "um padrão cronológico de organização dos conteúdos, no qual prevalece uma concepção de tempo linear como única possibilidade de organizar o processo histórico" (ARAÚJO, 2014, p. 127). Inquietar-se perante tais concepções constitui, possivelmente, atitude imprescindível para alcançarmos outras histórias e experiências ignoradas, que, em face da defesa genérica do manto da diversidade, subsumiram 
as condições necessárias ao convívio intercultural. Além destas reflexões, buscamos ainda aporte nos fundamentos da pesquisa etnográfica em educação.

A etnografia tem sua origem na Sociologia e na Antropologia e, por isso, utiliza-se de relatos descritos de pessoas, situações e acontecimentos. André (1995) afirma que, por meio de técnicas etnográficas de observação participante e de entrevistas intensivas, é possível documentar o não-documentado, ou seja, desvelar os encontros e desencontros que permeiam o cotidiano escolar. Nesta perspectiva, no trabalho de campo, valemo-nos de instrumentos que nos auxiliaram na coleta de dados, como anotações em diário de campo, mediante a imersão na escola investigada e as observações de aulas de história e análise de uma atividade realizada com os jovens estudantes do Ensino Médio. Conforme Vianna (2007), a observação é uma das mais importantes fontes de informações em pesquisas qualitativas em educação. Dessa forma, procuramos registrar as anotações realizadas nas visitas a escolas e, em particular, das aulas de história, de forma detalhada, com o intuito de reunir o máximo de dados oriundos da observação.

Convém ressaltar, no entanto, que a pesquisa didáticohistórica, segundo Cardoso (2008), não é o discurso de um antropólogo sobre um contexto familiar que ele precisa estranhar ou a crítica de um pedagogo à forma de organização das aulas do ponto de vista das ciências da educação. É um discurso de um profissional da cultura histórica sobre essa mesma cultura, que tem um grande impacto. Uma pesquisa de campo didáticohistórica jamais pode ignorar ou mesmo relegar a segundo plano os conteúdos tratados numa aula. O que ocorre na sala de aula é apenas parte de um todo mais amplo, que engloba múltiplas elaborações da História sem forma científica. É só parte da cultura histórica, chamada de história escolar, a qual mantém relações indissociáveis com outras expressões dessa cultura.

O desenvolvimento da investigação pressupõe diálogos constantes entre escola e universidade, por defendermos que a aproximação destes dois espaços pode contribuir para o processo 
de ensino e de aprendizagem, bem como para a constituição de sentido e apreensão do passado por parte de jovens estudantes do Ensino Médio, pois a sala de aula não se limita a um lugar de reprodução, mas também de produção de conhecimentos. Sendo assim, propomos ouvir professores e alunos e, junto aos integrantes da pesquisa, planejar aulas que recorram aos usos de diferentes fontes e linguagens, cuja premissa consistisse em transcender parâmetros normativos de paradigmas eurocêntricos.

\section{Ensino Médio, cenário e sujeitos: algumas considerações}

De acordo com Krawczyk (2014), o Ensino Médio no ocidente, assim como no Brasil, surge e se expande até a primeira metade do século $X X$, configurando-se de forma dual. De um lado, a formação de mão de obra qualificada, de outro, a formação das elites políticas e profissionais, com finalidade propedêutica. Isso quer dizer que, para alguns, preparava-se para a ascensão ao alto saber produzido pela humanidade e, para 'outros', o foco era nas habilidades profissionais. A natureza estritamente propedêutica durou até 1930. Com a ampliação do acesso à escola, como consequência da industrialização do país, o Ensino Médio passa ter um forte acento na profissionalização. A autora, ao apresentar o histórico do Ensino Médio no Brasil, evidencia que este passou por diversas reformas caracterizadas pela tensão entre a universalização e seleção.

É possível perceber que o processo de construção da identidade do Ensino Médio no Brasil é marcado por dissensos. Neste âmbito, ressaltamos as considerações de Arroyo (2014, p. 57), ao declarar que todo projeto de reestruturação curricular do Ensino Médio que pretenda definir expectativas e normas 'do alto', não reestrutura e nem inova o ensino. É necessário auscultar as escolas, seus coletivos docentes e discentes. É preciso reconhecer que, nas escolas de educação básica, há práticas inovadoras de que são atores professores e estudantes.

Ao buscarmos compreender a proposta do Ensino Médio, recorremos a documentos oficiais como a Lei de Diretrizes e 
Bases da Educação Nacional - LDB (1996), a qual ressalta que a educação básica tem como finalidade desenvolver o estudante e assegurar-Ihe a formação comum indispensável para o exercício da cidadania e fornecer-lhe meios para progredir no trabalho e em estudos superiores; os Parâmetros Curriculares Nacionais - PCNs do Ensino Médio definem as bases legais para a reforma desse nível de ensino e as três áreas disciplinares que orientam o trabalho docente. A primeira está organizada em torno de: "linguagens, os códigos e suas tecnologias", com os conhecimentos disciplinares de língua portuguesa, língua estrangeira moderna, educação física, arte e informática. As "ciências da natureza, da matemática e suas tecnologias" compõem a segunda área, por meio do campo disciplinar da biologia, da física, da química e da matemática. A terceira área, "ciências humanas e suas tecnologias", agrupa os conhecimentos de história, geografia, sociologia, antropologia, política e filosofia. $O$ documento não estabelece os conteúdos a serem trabalhados, mas competências que devem ser desenvolvidas pelos jovens estudantes.

Segundo o documento, as competências abrangem a capacidade de abstração, o desenvolvimento do pensamento sistêmico, da criatividade, da capacidade de refletir sobre múltiplas alternativas para a solução de problemas. Estas competências são consideradas condições para o exercício da cidadania em uma sociedade democrática.

As Diretrizes Curriculares Nacionais para o Ensino Médio, Parecer CNE/CEB, 05/2011, destacam que cabe ao Ensino Médio a preparação básica para o trabalho e a cidadania do educando para que este possa continuar aprendendo. É papel do Ensino Médio aprimorar o educando como pessoa humana, incluindo a formação ética, o desenvolvimento intelectual e o pensamento crítico. No Artigo $5^{\circ}$, ressalta:

O Ensino Médio, em todas as suas formas de oferta e organização, baseia-se em: I - Formação integral do estudante. II - Trabalho e pesquisa como princípios educativos e pedagógicos, respectivamente. III - Educação em direitos humanos como princípio 
nacional norteador. IV - Sustentabilidade ambiental como meta universal. V - Indissociabilidade entre educação e prática social, considerando-se a historicidade dos conhecimentos e dos sujeitos do processo educativo, bem como entre teoria e prática no processo de ensino-aprendizagem. VI - Integração de conhecimentos gerais e, quando for o caso, técnico-profissionais, realizada na perspectiva da interdisciplinaridade e da contextualização. VII - Reconhecimento e aceitação da diversidade e da realidade concreta dos sujeitos do processo educativo, das formas de produção, dos processos de trabalho e das culturas a eles subjacentes. VIII - Integração entre educação e as dimensões do trabalho, da ciência, da tecnologia e da cultura como base da proposta e do desenvolvimento curricular. (BRASIL, 2011, p. 57).

A análise do documento evidencia avanços, ao reconhecer professores e jovens estudantes como sujeitos da ação educativa e destacar a importância de historicidade dos conhecimentos de diferentes atores no processo educativo. As Diretrizes aludem à diversidade histórico-cultural dos jovens e propõem, no Art. 14, que a organização do Ensino Médio deve oferecer tempos e espaços próprios para estudos e atividades que permitam itinerários formativos opcionais e diversificados.

O Plano Nacional da Educação - PNE (2014) ${ }^{4}$, aprovado pela Lei $n^{\circ}$. 13.005, de 25 de junho de 2014, destaca a importância da educação na formação cidadã das crianças e jovens, ao arrolar em seu Artigo $2^{\circ}$, as seguintes diretrizes: "III - superação das desigualdades educacionais, com ênfase na promoção da cidadania e na erradicação de todas as formas de discriminação; V - formação para o trabalho e para a cidadania, com ênfase nos valores morais e éticos em que se fundamenta a sociedade.". O

4 A Emenda Constitucional n. 59/2009 mudou a condição do PNE, que passou de uma disposição transitória da LDB 9394/96, para exigência constitucional com periodicidade decenal. O Plano passou a ser considerado o articulador do Sistema Nacional de Educação, com previsão do percentual do Produto Interno Bruto - PIB para financiamento. O PNE deve ser a base para elaboração dos Planos estaduais, distritais e municipais. 
PNE apresenta 20 metas a serem cumpridas ao longo de seu período de vigência, e, especificamente no que tange ao Ensino Médio, apresenta como metas, universalizá-lo até 2016, incluindo a população de 15 a 17 anos, e elevar a taxa de matrícula no Ensino Médio para 85\%.

Referente à História escolar, cabe ao professor auxiliar os jovens estudantes a construir o sentido do estudo da história, oferecer-Ihes um contraponto que lhes permita (re)significar suas experiências no contexto e na duração histórica da qual fazem parte. Para atingir esse objetivo, as Orientações Curriculares para o Ensino Médio - OCEM -, publicadas em 2006, apontam como princípios estruturadores do currículo os seguintes itens: a interdisciplinaridade, a contextualização, a definição de conceitos básicos da disciplina, a seleção de conteúdos e sua organização, as estratégias didático-pedagógicas.

A proposta curricular para o ensino de história prevê o aperfeiçoamento de competências e habilidades dos estudantes. Reforça a importância de desenvolver os conhecimentos históricos, bem como a preocupação de localizar, no campo da história, questões que remetam ao tempo em que vivemos, como a identificação da heterogeneidade, a distinção das particularidades da cidadania cultural, a política da convivência e da tolerância em relação ao diferente. Sugere uma proposta curricular fundamentada em um multiculturalismo conservador, assimilacionista. Ou seja, todos são chamados a participar do sistema escolar, mas sem colocar em questão o seu caráter monocultural e homogeneizador.

Indo ao encontro com esta perspectiva concordamos com Mclaren (2000) ao alertar os educadores para a necessidade de incorporar e ir além da diversidade. Conforme o autor, o discurso da diversidade e da inclusão é, muitas vezes, prejudicado com afirmações camufladas de assimilação e consenso, que servem como apoio aos modelos democráticos neoliberais de identidade, buscando assimilar as diferenças, tornando o diferente supostamente semelhante. $O$ autor desafia a afirmação aceita de que, para superar tal modelo, bastam iniciativas a serviço da 
inclusão de populações minoritárias. Isto, segundo ele, poderá apenas fragmentar a realidade, fazendo com que os indivíduos aceitem, facilmente, viver a mentira de uma sociedade não-racista.

Consideramos fundamental que a história, em situação escolar, possibilite questionar as diferenças e desigualdades construídas ao longo da história entre multiplicidade de experiências socioculturais, étnico-raciais, de gênero, condição sexual, entre outros. A este respeito, Candau (2014) reitera que o desafio é não reduzir a igualdade à padronização, nem a diferença a um problema a resolver. Isso significa transformar a diversidade em uma vantagem pedagógica.

Pautados nessas considerações e desafios na formação de jovens do Ensino Médio, partimos para a segunda fase de nossa pesquisa: a observação no espaço escolar. A pesquisa está sendo realizada na Escola Estadual Governador Israel Pinheiro, localizada na Av. Geraldo Alves Tavares, $n^{\circ}$. 1.338, Setor Universitário, Ituiutaba, MG. Em 2014, a escola atendia a uma média de 1.500 alunos, distribuídos em 39 turmas, sendo 16 no turno matutino, 16 no vespertino e 7 no noturno. Trabalhavam na escola 100 funcionários, destes, 7 professores de História. Fizeram parte direta da nossa investigação três turmas compostas por jovens estudantes do primeiro ano do Ensino Médio do turno vespertino, totalizando 95 alunos e um professor de História.

Na primeira parte da investigação, focamos os estudos em documentos oficiais - Parâmetros Curriculares Nacionais para o ensino de História - PCNs; Diretrizes Curriculares Nacionais para o Ensino Médio - DCNEM; Plano Nacional de Educação - PNE (2014); Projeto Político Pedagógico da escola; e o Planejamento anual do professor. Concomitante à análise dos documentos, realizamos uma revisão bibliográfica sobre temáticas relativas ao ensino de história, estudos pós-coloniais e sobre o potencial de diferentes fontes e linguagens da cultura contemporânea. $O$ professor, sujeito da pesquisa, participou ativamente dos estudos realizados. O segundo passo consistiu no planejamento de aulas, recorrendo a diferentes fontes e linguagens. Todas as atividades foram acompanhadas e registradas. 
Com base nas observações e diálogos com o conjunto dos jovens estudantes, buscamos compreender suas expectativas, opiniões a respeito da escola e do ensino de história. Constatamos que o grupo era constituído pessoas negras, pardas, brancas, de diferentes religiões, diversos gostos musicais, múltiplas trajetórias e experiências de vida. Estes aspectos ratificam aquilo que pesquisas de Dayrell e Carrano (2014) expressam, ao sugerir como mais adequado referir-se a "juventudes" no plural, por avaliarem que são muitas as formas de ser e de se experimentar o termo de juventude.

Em perspectiva semelhante, Sposito (1997) declara ser quase impossível recorrer ao uso da categoria "jovem" de maneira generalizada nas pesquisas voltadas a este segmento. A autora concebe a "juventude" como categoria socialmente constituída, que atende a fenômenos existentes, possui uma dimensão simbólica, mas que também deve ser analisada a partir de outras dimensões: materiais, históricas e políticas, nas quais a complexidade da produção social se desenvolve. Assim, justifica-se a opção de usarmos o conceito no plural, juventudes, sem desconsiderar as diferenças e desigualdades em se insere historicamente a categoria "juventude".

O grupo de jovens participantes da pesquisa possuía de 15 a 17 anos, parte destes eram trabalhadores(as), dado também constatado por Dayrell (2007), Dayrell e Carrano (2014), quanto à juventude brasileira não poder ser caracterizada pela moratória em relação ao trabalho. Para estes jovens, o trabalho é o que garante manter a condição juvenil, que pode ser compreendida tanto pelas expressões culturais quanto pela sociabilidade. Os jovens estudantes do Ensino Médio, sujeitos desta pesquisa, consideravam a música, a dança, a turma de amigos como elementos que os caracterizam como jovens. Afirmaram que a televisão e a música constituem modalidades de entretenimento muito utilizados em seus cotidianos.

Constatamos, ainda, que a maioria acessava e utilizava com frequência ferramentas tecnológicas, como internet, jogos eletrônicos, dentre outros. Consideram a família uma instituição 
importante para a formação de suas identidades. Quanto aos tipos de leitura, a maioria lia apenas o livro didático, poucos disseram ler livros de romance, aventuras ou suspense. Alguns afirmaram que sempre liam histórias em quadrinhos ou mangás. Tais questões revelam que indícios de diferentes linguagens e mídias fazem parte da vida prática dos jovens estudantes. Nesse sentido, indicam potenciais a serem explorados pela escola no processo de ensinar e aprender.

É papel da escola empreender ações com o intuito de mobilizar os jovens estudantes para as diversas leituras. Ao final do Ensino Médio, é imperativo que os jovens estudantes desenvolvam o raciocínio lógico, a capacidade argumentativa e discursiva, e tais habilidades só podem ser efetivadas por meio de atividades de leitura crítica. Para Mclaren e Giroux (2000),

Os estudantes precisam aprender a ler não como um processo de submissão à autoridade do texto, mas como um processo dialético de compreensão, de crítica e de transformação. Eles precisam escrever e reescrever as histórias nos textos que leem, de forma a serem capazes de identificar e desafiar, se for o caso, as maneiras pelas quais tais textos funcionam ativamente para construir suas histórias e vozes. Ler um texto deve ser uma maneira de aprender a fazer escolhas, a construir uma voz, e a localizar a si próprios na história. Isso implica intervir de forma diferenciada em sua autoformação e na formação dos outros. (MCLAREN; GIROUX, 2000, p. 38).

Em sala de aula, é fundamental que o professor, ao trabalhar com a leitura, mobilize os estudantes a interrogar os textos pelo que não dizem, pelos seus silêncios estruturados. A leitura, nessa perspectiva, torna possível desestabilizar a constelação de fatos reificados que buscam legitimar as relações existentes de poder e privilégio entre grupos dominantes. Conforme Mclaren e Giroux, compete aos professores ensinar os estudantes a ler, interpretar e criticar. Ao ler, produzimos um texto dentro de um texto, ao interpretar, criamos um texto sobre um texto; e, ao criticar, 
construímos um texto contra um texto (MCLAREN; GIROUX, 2000, p. 45).

Muito embora as sociedades contemporâneas sejam marcadas pelo uso intensivo de recursos tecnológicos, assim como da informação via meios de comunicação, a escola permanece como lócus formativo para a juventude brasileira. De acordo com Guimarães e Silva Júnior (2012), a instituição escolar é um espaço que, ao se expandir, constituiu um lugar de intensificação e abertura das interações com o outro. Portanto, um caminho privilegiado para a ampliação da experiência de vida dos jovens. No entanto Dayrell (2007) alerta que, para muitos jovens, a escola se mostra distante dos seus interesses, reduzida a um cotidiano enfadonho, com conteúdos, práticas pedagógicas e professores que pouco acrescentam à sua formação.

Os jovens pesquisados afirmaram que, em suas aulas, não utilizavam fontes culturais diversas, restringindo-se, basicamente, ao livro didático. A roda de amigos e os esportes constituíam meios aos quais os jovens tinham mais acesso. Tais constatações evidenciam a necessidade de iniciativas que promovam e ampliem o diálogo entre escola e outros espaços de convivência dos jovens, e, deste modo, despertem interesse e sentido à busca de novos conhecimentos capazes de transformar suas visões de mundo. Conforme Charlot (2001), a escola só desempenhará com legitimidade seu papel se vier a ser, antes de tudo, um espaço de reconhecimento recíproco. A escola deve ser um espaço instigante, que propicie aos jovens a religação de saberes de sua cultura com outras realidades, tempos e historicidades.

Dentre os jovens que responderam à pesquisa, sobre o ensino de história, a maioria afirmou que era "excelente". Para a maior parte destes, no entanto, a história é "um meio de entender a vida". Muitos estudantes declararam que o professor ensinava história buscando relacionar com a vida dos jovens. Trabalhava com o livro didático, canções e filmes. O professor de história, colaborador da investigação, lecionava em dois colégios, sendo um na rede pública estadual e o outro particular com preceitos católicos. 
Observamos que o professor era bastante respeitado pelos alunos, detentor de postura carismática e uma narrativa envolvente. Procurava, com frequência, introduzir em suas aulas os estudos realizados ao longo do projeto, recorrer à representação de ideias, analogias, ilustrações, exemplos e explicações como modo de representar e formular os conteúdos com o intuito de torná-los compreensíveis para os estudantes.

Ao longo do ano de 2014, foi possível perceber o comprometimento do professor com o projeto desenvolvido. $\mathrm{Na}$ continuação deste artigo, apresentamos algumas atividades produzidas com os jovens estudantes, sujeitos desta investigação.

\section{A história na sala de aula: o potencial das diferentes fontes e linguagens}

Partimos do princípio de que o conjunto de conceitos e orientações teórico-metodológicas é imprescindível no processo de ensinar e de aprender história. O conhecimento histórico escolar constitui-se de conhecimentos da disciplina, dos problemas contemporâneos e das concepções e interesses dos estudantes. Tais elementos devem ser considerados de forma equitativa. Concordamos com Seffner (2000), ao afirmar que falar em teoria é perceber que a história não recupera o passado, mas constrói o passado, a partir de preocupações do presente, com reflexos nos projetos futuros. A preocupação com a metodologia diz respeito aos procedimentos que devemos adotar, próprios do ofício de historiador. A teoria e a metodologia estão carregadas e carregam uma visão de mundo. Para Mclaren e Giroux (2000), a teoria, em alguns casos, informa diretamente a prática; em outros, a prática reestrutura a teoria como uma força fundamental para a mudança. Em algumas situações, a teoria (no sentido mais limitado da prática de produzir narrativa e retórica) oferece um refúgio para pensarmos além das formas correntes de prática, de modo a visualizar aquela que "ainda não é".

Ao planejar as aulas, levamos em conta os elementos apreendidos ao longo das observações dos diálogos com os 
jovens e com professores. As experiências, os saberes, os gostos dos jovens precisavam estar presentes ao longo das aulas. Um grande desafio foi imposto pelo professor: não poderíamos fugir dos conteúdos relacionados do Currículo Básico Comum - $\mathrm{CBC}^{5}$ -, documento que orienta o que deve ser ensinado, pois a equipe pedagógica da escola supervisionava ativamente o cumprimento ou não desta normatização efetivada na escola. Os conteúdos estabelecidos por esse documento denotam o predomínio de uma perspectiva eurocêntrica. Dessa forma, investimos em táticas que nos permitissem trabalhar os conteúdos curriculares expressos no CBC e, ao mesmo tempo, chamar a atenção para as outras interpretações dos conteúdos de história. Assim, optamos por planejar as aulas sob o formato de sequências de ensino.

Segundo Aguiar Júnior (2004), a sequência de ensino consiste em uma organização coerente de atividades que possibilitem mobilizar os estudantes a aprender história de forma contextualizada. A sequência compõe-se de 4 momentos: problematização, desenvolvimento da narrativa, aplicação de novos conhecimentos e reflexão/síntese. A primeira etapa tem como objetivo captar os saberes dos estudantes sobre a temática abordada e mobilizá-los a ampliar seus conhecimentos. A segunda é o momento em que se desenvolve a exploração dos conteúdos e conceitos, pode-se recorrer às aulas expositivas dialogadas, leitura individual e trabalhos coletivos. Na terceira, buscamos diferentes fontes e linguagens para que os jovens possam articular os conhecimentos apreendidos. Por fim, os estudantes realizam uma atividade final, procurando sintetizar os conhecimentos adquiridos. Registramos, a seguir, uma experiência realizada ao longo de 2014.

No planejamento da sequência, seguimos o CBC, porém tínhamos o desafio de reforçar as reflexões sobre outras histórias. O tema a ser trabalhado era: "O Encontro das Diferenças e a Construção da Imagem do Outro”. Ao longo das aulas, procuramos

5 O CBC foi instituído pela Resolução da SEE-MG, n. 833, em 24 de novembro de 2006. 
mediar a construção, por parte dos alunos, dos seguintes conceitos históricos: colonização, cultura, etnocentrismo e resistência. Segundo Bezerra (2012), a compreensão dos conceitos é imprescindível para a formação histórica de estudantes do Ensino Médio.

Na primeira etapa da sequência, com o intuito de conhecer os saberes dos jovens estudantes sobre a temática, questionamos: como vivem os indígenas brasileiros? Como se deu o processo de colonização pelo olhar do indígena? Ao longo do diálogo, foi possível evidenciar que os estudantes sabiam muito pouco sobre a história e culturas indígenas. As respostas que predominaram relacionavam-se ao processo de colonização, no qual os indígenas foram vencidos e, praticamente, dizimados. Apenas um jovem comentou, de forma fragmentada, mencionando uma reportagem televisiva, sobre o movimento de luta pela terra de povos indígenas da região norte do Brasil.

As respostas dos alunos nos permitem concordar com Martins (2011), ao afirmar que tanto os livros didáticos como a historiografia tradicional reproduzem, de modo simplificador e estereotipado, a imagem das populações autóctones do território definido como brasileiro. Essa autora ressalta que tal perspectiva acentuou grande evidência à "Visão dos Vencidos". As obras que se filiam a esta corrente tratam de testemunhos dos "sobreviventes", abatidos por um "profundo trauma", bem como os efeitos da "destruição da cultura indígena" tiveram forte aceitação no âmbito escolar. De acordo com a autora, é preciso destacar que os povos que eram tidos como fadados à extinção hoje estão vivos, atuantes, presentes, organizados e cobrando do Poder Público a implementação de seus direitos, não são apenas sobreviventes, mas viventes.

Ainda na etapa da problematização, trabalhamos com a canção "Chegança", de Antônio Nóbrega, com o intuito de mobilizar os jovens estudantes a empreender reflexões sobre

6 Letra da canção disponível no site: <http://letras.mus.br/antonionobrega/68957/>. Acesso em: 27 fev. 2015. 
a temática. De acordo com Guimarães (2012), ensinar História por meio de canções é um grande desafio e requer algumas considerações. Para a autora,

A linguagem poética expressa outra forma de ver, escrever e expressar sentimentos sobre variados temas, questões, fatos, sujeitos e práticas sociais e culturais. Seduz, age sobre nós, intervém, nos provoca. Assim, pode fornecer pistas para alargar a compreensão dos temas históricos com beleza e sensibilidade. $A$ incorporação de canções desperta o interesse dos alunos, motivaos para as atividades, sensibiliza-os em relação aos diversos temas e desenvolve a criatividade. (GUIMARÃES, 2012).

A canção "Chegança" foi composta, em 1999, por Antônio Nóbrega e Wilson Freire, na ocasião das comemorações dos "500 anos" do Brasil, momento em que houve considerável discussão em torno visão eurocêntrica e a visão dos autóctones. A canção enfatiza, por meio seu enredo, uma narrativa que menciona a visão de diversos povos autóctones sobre o que viria a ser o Brasil após a chegada dos europeus.

Para a análise da canção, foi proposta uma atividade em duplas, na qual os estudantes deveriam refletir sobre as seguintes questões: qual é o tema da canção? De que trata a letra? Como o autor desenvolve o tema? Qual a posição que ele assume? Como você interpreta a canção? Quais as hipóteses que são possíveis de ser levantadas? Quais são os indicativos que remetem à época estudada? Quais partes da letra se relacionam com o tema em estudo? Vale destacar que o trabalho do professor em sala de aula deve considerar as especificidades do trabalho do historiador, levando em conta a realidade própria do Ensino Médio.

Nessa atividade, observamos que a maioria dos estudantes teve dificuldades na realização da análise. Foram entregues 51 trabalhos, destes, oito mencionaram que o tema da canção estava relacionado ao "descobrimento" do Brasil; 43 registraram que a temática envolvia a "invasão" ou "conquista" do Brasil. Ponderamos que as discussões realizadas na sala de aula 
instigaram a posicionamentos críticos acerca da temática na maioria dos estudantes.

De modo geral, os textos apresentados pelos estudantes exprimem reflexões que julgamos básicas sobre a temática. Porém estimularam indagações, debates e argumentos que avaliamos indicativos do potencial do trabalho com diversificadas linguagens, bem como estas podem mobilizar os estudantes ao engajamento em exercícios interpretativos, orientados pela mediação do professor, nos quais atuam como investigadores e agentes do conhecer. Ao longo das aulas, procurou-se estimular os jovens a refletir sobre a cultura indígena. O maior desafio foi dar inteligibilidade às diferenças, para que estas não se transformem em indiferença. Assim, tais procedimentos podem fazer parte do cotidiano das aulas de história, como atividades que exigem reflexões mais profundas, e isso somente é possível por meio de trabalho metodicamente pensado no processo de planejar que inclua o estudante como participe da construção do conhecimento. Esta questão foi discutida com o professor da turma, que percebeu a necessidade do planejamento constante e que as linguagens oferecem grande potencial, mas que precisam ser usadas de maneira mais contundente.

Quanto à segunda etapa da sequência de ensino, o professor apresentou uma narrativa histórica acerca da política mercantilista, suas características e objetivos; a aliança da burguesia com a monarquia. Ressaltou as representações dos europeus sobre o "Novo Mundo". Problematizou a expressão "Novo Mundo ou Outro Mundo?" Retomou a questão das diferenças culturais entre os colonizadores e colonizados. A respeito de questões dessa ordem, Lautier (2011) argumenta que,

A sala de aula é o lugar legítimo para elaborar conhecimentos mais formalizados, para escolher, classificar, reorganizar as informações propostas por todos os outros canais de vulgarização. No âmbito de uma aula de história, cabe aos professores suscitar as condições para passar da simples narrativa à narrativa histórica, ou pelo menos a uma forma aligeirada da narrativa histórica. (LAUTIER, 2011, p. 51). 
Após a exposição e o debate com os estudantes foi realizado o estudo no livro didático. Dentre outros procedimentos, o professor propôs explorar os seguintes aspectos: a rota marítima proposta por Colombo; refletir sobre o porquê do nome do continente ser América; problematizar o subtítulo: Brasil: descobrimento ou achamento? Discutir o Tratado de Tordesilhas, questionando sobre como os europeus percebiam os povos da América; identificar aspectos de culturas de povos indígenas do Brasil; problematizar a noção de "antropofagia tupi" e refletir sobre o conceito de resistência; localizar, geograficamente, os povos incas, maias e astecas; discutir a expressão "A espada e a cruz: conquista espanhola".

Na fase da "aplicação de novos conhecimentos", foram encaminhadas atividades que apresentassem obstáculos cognitivos para os alunos, de forma que eles necessitassem usar as referências teóricas estudadas nas atividades de "desenvolvimento da narrativa". A expectativa era de que os alunos conseguissem aplicar os conhecimentos para atribuir relações entre o conteúdo e os problemas apresentados, solucionando-os. Para tanto, optamos pelo trabalho com documentos.

Segundo Bittencourt (2004), fazer a análise e comentário de um documento corresponde a: descrever o documento, isto é, indicar as informações que ele contém. Mobilizar os diversos saberes para: explicar o documento, fazer associações entre as informações e saberes anteriores; situar o documento no contexto e em relação ao seu autor; identificar a natureza desse documento e também explorar esta característica. Para chegar a identificar os limites e o interesse do documento e ser capaz de criticá-lo. O professor apresentou dois documentos: um trecho da carta de Pero de Magalhães Gandavo - "Tratado da Terra do Brasil, século XVI"7e um relato de Jean de Léry, "um velho índio Tupinambá no século XVI"8. Após a primeira leitura, formulou

7 Disponível em:<http://educador.brasilescola.com/estrategias-ensino/ etnocentrismo-colonizacao.htm>. Acesso em: 10 jul. 2014.

8 Adaptação disponível no link: $<$ http://www.iande.art.br/textos/velhotupinamba. 
questões fundamentadas na proposta de Circe Bittencourt. Procurou relacionar os documentos com o que foi anteriormente estudado, ou seja, com a análise da canção "Chegança" e as atividades do livro didático.

O conteúdo dos dois documentos discorre sobre percepções acerca dos indígenas, enfatizando que viviam "bestialmente sem ter conta, nem peso nem medida". Posterior à leitura e análise inicial de cada um dos documentos, o professor indicou três atividades: 1) Qual a diferença entre os dois documentos? 2) $O$ autor do documento 1 trabalha com a ideia de exclusão, etnocêntrica, pois o outro é visto pelo que ele não tem em relação ao europeu. Cite trechos do texto que exemplifiquem esta característica do autor. 3) De acordo com o documento 2, quais as diferenças apontadas pelo índio Tupinambá entre sua cultura e a cultura europeia, relacionadas à concepção sobre o trabalho e a exploração da terra?

O trabalho foi realizado em grupos compostos por três alunos, dos quais resultaram 28 atividades que analisamos como parte dos objetivos de nossa investigação. Destes, 15 grupos desenvolveram satisfatoriamente as atividades. Pelas respostas, depreende-se que compreenderam as diferenças entre os documentos, problematizaram o conceito de etnocentrismo e evidenciaram as diferenças culturais entre colonizador e colonizado. Nas atividades de outros dez grupos, no entanto, constatou-se pelas respostas, uma compreensão parcial da atividade solicitada, sendo que a maior dificuldade foi estabelecer, de maneira clara, a diferenças entre os dois documentos. Apenas três grupos não conseguiram responder à atividade proposta, prenderam-se, excessivamente, aos textos e copiaram, de forma aleatória, partes do documento.

Por fim, na fase da "reflexão/síntese", foi solicitada a produção de um texto assinalando os conceitos históricos: colonização, cultura, etnocentrismo e resistência. Os textos produzidos pelos estudantes denotam a dificuldade dos jovens em desenvolver

$\underline{\mathrm{htm}}$. Acesso em: 10 jul. 2014. 
uma escrita articulada. Dos 28 trabalhos produzidos, três grupos apresentaram a definição de conceitos, 17 procuraram elaborar os textos recorrendo aos conceitos assinalados, mas sempre priorizavam alguns e ignoraram outros. Apenas oito grupos conseguiram desenvolver textos pautando-se nos conceitos sugeridos.

De modo geral, verificamos o desafio de ensinar e aprender história na perspectiva de desenvolver uma escrita argumentativa. Um exercício necessário ao longo da educação básica, pois é inadmissível que estudantes concluam o Ensino Médio sem conseguir ler e escrever com fluência, pois se trata de competências fundamentais para leitura do mundo. Conforme Seffner (2000), quem lê e interpreta o mundo é que escreve e o transforma.

\section{Considerações Finais}

Lidar com a formação histórica de jovens estudantes do Ensino Médio, assim como propor mudanças ao processo de ensino e aprendizagem, perpassa por uma gama de fatores, desde a redefinição de fundamentos e pressupostos teóricometodológicos da história como disciplina e da plausibilidade de parâmetros epistemológicos decorrentes da modernidade europeia, de pressupostos normalizadores estabelecidos por documentos oficiais. E, fundamentalmente, deter-se a refletir sobre os sentidos e significados de conteúdos e conceitos atinentes ao que se ensina e se apreende no ensino de história. Como exemplo, retomamos a discussão apontada no início deste texto a respeito da diversidade $\mathrm{x}$ intercultural.

A pesquisa nos permitiu ainda perceber como a aprendizagem histórica, por parte dos jovens estudantes do Ensino Médio, ocorre de forma desigual, ou seja, alguns evidenciam maior facilidade e outros, enquanto outros enfrentam dificuldades basilares em apreender os conceitos e conteúdo essências para pensar a historicidade de experiências temporais. Concordamos com Lautier (2011) ao destacar três fatores responsáveis por 
essa desigualdade: o domínio da linguagem, a imagem de si na condição de aluno e as esperas ligadas ao contrato didático. $\mathrm{O}$ domínio das formas de linguagens, a leitura interpretativa são essenciais para o estudante aprender história. Nesse sentido, cabe ao professor persistir no exercício da leitura. Para ensinar história, é importante que o docente use da arte de seduzir, e, assim, contribua para que o aluno elabore um sentimento de pertença à história. É neste sentido que Pais (1999) argumenta que a cientificidade da História não impossibilita que esta se arme com estratégias de sedução. Ao recorrer a variadas fontes e linguagens, o desafio do professor é mobilizar o aluno para a exploração e análise de noções de tempo, possíveis a partir da interpretação de fontes históricas, disponíveis em diferentes linguagens e, por meios destas, apreender outras histórias, não como simples complemento de informação, ou confirmação de uma "história única".

Admitimos que os saberes escolares têm um status específico. Não são totalmente científicos, nem completamente profanos, são produtos de intencionalidade e, como tal, são construção histórica. Um conteúdo de saber transmitido e aprendido possui formas singulares. Constitui desafios à didática da história, conhecer e problematizar como o aprendizado histórico se efetiva nas salas de aula, como os jovens aprendem história. Os primeiros resultados dessa pesquisa com os estudantes nos levam a repensar a relação professor/aluno, o tipo de aprendizado histórico produzido mediante esta relação e como é possível associar o conhecimento produzido por eles com a vida prática cotidiana. A partir disto, formularmos proposições à didática da história.

A didática da história, como campo de saber, deve insistir em estreitar o diálogo entre o trabalho dos historiadores e a educação escolar e não se limitar à transposição do conhecimento histórico acadêmico para os estudantes da educação básica. Defendemos a proposição de que a didática da história, deve estar compromissada com a análise de formas e funções do raciocínio e do conhecimento histórico na vida cotidiana e prática. Isto inclui o papel da história na opinião pública, os usos da história nos meios 
de comunicação de massa, bem como considera as possibilidades e limites das representações históricas nas diferentes fontes e linguagens.

Acreditamos que os conteúdos históricos nas salas de aula devem ser resultados de problemas, debates, pesquisas e polêmicas. Nesta perspectiva, a finalidade do ensino de história é formar cidadãos críticos e responsáveis, capazes de compreender a complexidade e tomar parte do debate democrático. Assim, as aulas de história não podem se caracterizar como meras exposições dialogadas, mas como efetiva interação entre estudantes, professores, documentos, fontes variadas e diferentes linguagens. As proposições da didática da história podem, certamente, contribuir para a produção de conhecimentos históricos e a formação de sujeitos engajados e cientes de seu compromisso social e político.

\section{Referências}

ABRAMO, Helena Wendel; BRANCO, Pedro Paulo Martoni (Orgs.). Retratos da juventude brasileira. São Paulo: Instituto Cidadania; Editora Fundação Perseu Abramo, 2005.

ARAÚJO, Cinthia. O trabalho de tradução no saber histórico escolar: diálogos interculturais possíveis. In: MOREIRA, Antonio Flávio; CANDAU, Vera Maria (Orgs.). Currículos, disciplinas escolares e culturas. Petrópolis, RJ: Vozes, 2014.

ARROYO, Miguel. Repensando o Ensino Médio: Por quê? In: DAYRELL, Juarez; CARRANO, Paulo; MAIA, Carla Linhares (Orgs.). Juventude e Ensino Médio. Belo Horizonte. Editora UFMG, 2014.

BRASIL. Orientações curriculares para o Ensino Médio. Ciências humanas e suas tecnologias. Secretaria de Educação Básica. Brasília: Ministério da Educação, Secretaria de Educação Básica, 2006. 
BRASIL. Plano Nacional de Educação. Ministério da Educação/ Secretaria de Articulação com os Sistemas de Ensino. Brasília: Ministério da Educação; SASE, 2014.

CANDAU, Vera Maria. Educação intercultural: entre afirmações e desafios. In: MOREIRA, Antonio Flávio; CANDAU, Vera Maria (Orgs.). Currículos, disciplinas escolares e culturas. Petrópolis, RJ: Vozes, 2014.

CARDOSO, Oldimar. Para uma definição de Didática da História. Revista Brasileira de História, São Paulo, v. 28, n. 55, p. 153-170, 2008.

CHARLOT, Bernard (Org.). Os jovens e o saber: perspectivas mundiais. Porto Alegre: Artmed Editora, 2001.

DAYRELL, Juarez. A escola "faz" as juventudes? Reflexões em torno da socialização juvenil. Educação e Sociedade, Campinas, v. 28, n. 100 Especial, p. 1105-1128, out. 2007. Disponível em <http:// www.cedes. unicamp.br> . Acesso em: 10 set. 2014.

DAYRELL, Juarez; CARRANO, Paulo. Juventude e Ensino Médio: quem é esse aluno que chega à escola. In: DAYRELL, Juarez; CARRANO, Paulo; MAIA, Carla Linhares (Orgs.). Juventude e Ensino Médio. Belo Horizonte. Editora UFMG, 2014.

GUIMARÃES, Selva. Didática e prática de ensino de História: experiência, reflexões e aprendizado. 13 ed. rev. ampl. Campinas, SP: Papirus, 2012.

GUIMARÃES, Selva; SILVA JÚNIOR, Astrogildo Fernandes. Ser jovem no Brasil: trajetórias no campo e na cidade. Campinas, SP: Editora Alínea, 2012.

KRAWCZYK, Nora. Uma roda de conversa sobre os desafios do Ensino Médio. In: DAYRELL, Juarez; CARRANO, Paulo; MAIA, Carla Linhares (Orgs.). Juventude e Ensino Médio. Belo Horizonte. Editora UFMG, 2014. 
LAUTIER, Nicole. Os saberes históricos em situação escolar: circulação, transformação e adaptação. Educação e Realidade, Porto Alegre, v. 36, n. 1, p. 39-58, jan./abr., 2011.

MARTINS, Maria Cristina Bohn. As sociedades indígenas, a história e a escola. Antíteses, v. 2, n. 3, p. 153-167, jan./jun. 2009.

MCLAREN, Peter; GIROUX, Henry. Escrevendo das margens: geografias de identidade, pedagogia e poder. In: MCLAREN, Peter. Multiculturalismo revolucionário: pedagogia do dissenso para o novo milênio. Porto Alegre: Artes Médicas Sul, 2000.

MIGNOLO, Walter. Os esplendores e as misérias da 'ciência': colonialidade, geopolítica do conhecimento e pluri-versalidade epistêmica. In: SANTOS, Boaventura de Sousa (Org.). Conhecimento prudente para uma vida decente. 'Um discurso sobre as ciências'. Porto: Afrontamento, 2003. p. 631-671.

SANTOS, Boaventura de Sousa; MENESES, Maria Paula. (Orgs.) Epistemologias do Sul. São Paulo, SP: Editora Cortez, 2010.

SANTOS, Boaventura de. Para uma sociologia das ausências e uma sociologia das emergências. In: SANTOS, Boaventura de Sousa (Org). Conhecimento prudente para uma vida decente. Um discurso sobre as ciências revisitado. São Paulo: Cortez, 2004.

SEFFENER, Fernando. Teoria, metodologia e ensino de história. In: GUAZZELLI, Cesar Augusto Barcellos; PETERSEN, Sílvia Regina Ferraz; SCHIMIDT, Benito Bisso; XAVIER, Regina Célia. Questões de Teoria e Metodologia da História. Porto Alegre: Editora da Universidade, 2000. p. 257-288.

SPOSITO, Marília Pontes. Estudos sobre juventude e escolarização. Revista Brasileira de Educação, São Paulo, n. 5/6, p. 37-52, maio-ago./ set.-dez.1997. 
VAINFAS, Ronaldo et al. História: das sociedades sem Estado às monarquias absolutistas. São Paulo: Saraiva, 2010. v. 1.

VIANNA, Heraldo Marelim. Pesquisa em educação: a observação. Brasília: Líber Livro Editora, 2007.

Recebido em dezembro de 2015. Aprovado em junho de 2016. 